\title{
Long-term safety and efficacy of insulin degludec in the management of type 2 diabetes
}

This article was published in the following Dove Press journal:

Diabetes, Metabolic Syndrome and Obesity: Targets and Therapy

I October 2015

Number of times this article has been viewed

\author{
Philippe Thuillier' \\ Zarrin Alavi \\ Véronique Kerlan' \\ 'Department of Endocrinology, \\ Diabetology and Metabolic Diseases, \\ ${ }^{2}$ French Institute of Health and \\ Medical Research CIC 1412, Medical \\ University Hospital of Brest La Cavale \\ Blanche, Brest, France
}

Correspondence: Philippe Thuillier Department of Endocrinology, Diabetology and Metabolic Diseases, University Hospital Center of BREST La Cavale Blanche, Boulevard Tanguy Prigent, 29609 Brest Cedex, France

$\mathrm{Tel}+33298347119$

Fax +33 298347800

Email philippe.thuillier@chu-brest.fr

\begin{abstract}
Insulin degludec (IDeg) is a novel antiglycemic agent belonging to the therapeutic class of ultra-long duration basal insulin analogs. Its half-life and duration of action are 25 hours and 42 hours, respectively. This pharmacodynamic profile leads to a strict dosing schedule, ie, IDeg is injected at the same time each day to ensure optimal biological action and consistent glycemic control. According to the literature, IDeg provides glycemic control and nocturnal hypoglycemia reduction comparable with other long-acting analogs in type 2 diabetes mellitus. The risk of severe hypoglycemic episodes seems also to be reduced when using IDeg therapy; however, long-term follow-up is warranted for monitoring of possible but relatively infrequent adverse events. IDeg is also available in combination with aspart insulin and with liraglutide. The above preparations have been approved by the European Medicines Agency and other national health authorities. In 2012, the US Food and Drug Administration asked for a complementary study on IDeg-associated cardiovascular risk. Future prospective evaluation of large cohorts of patients with type 2 diabetes mellitus treated with IDeg, with long-term follow-up, can provide further relevant information on the safety of IDeg therapy.
\end{abstract}

Keywords: degludec insulin, hypoglycemia, $\mathrm{HbA}_{1 \mathrm{c}}$, safety, type 2 diabetes mellitus, basal insulin analog

\section{Introduction}

The European Medicines Agency and other national health authorities have recently given marketing authorization for a new ultra-long duration basal insulin analog, insulin degludec (IDeg), and its various preparations in combination with aspart insulin (IDegAsp) and with liraglutide (IDegLira) for the treatment of adults with diabetes mellitus. Currently, the most efficient glucose-lowering treatments for type 1 diabetes (T1DM) and type 2 diabetes (T2DM) in the event of oral antidiabetic drug failure are insulin glargine (IGla) and insulin detemir (IDet). Basal insulin analogs are in fact preferred to neutral protamine Hagedorn insulin because of their longer ${\text { duration of } \text { action }^{1} \text { and flatter action profile. }}^{2}$ They are also distinguished by their lower intrapatient variability in hypoglycemic action. ${ }^{2}$ Although to date there has been no randomized trial on the efficacy of long-acting basal insulin analogs with regard to reduction of severe hypoglycemia, long-acting basal insulin analog therapy has been demonstrated to confer comparable glycemic control of both overall and nocturnal hypoglycemia. ${ }^{3}$ Furthermore, their long-acting effect improves quality of life in patients with T1DM, allowing glycemic control through a single injection compared with the two injections needed when using neutral protamine Hagedorn insulin. Thus, use of these basal insulin analogs should become routine in clinical practice. 
Reduction of cardiovascular morbidity and mortality, along with efficacy in $\mathrm{HbA}_{1 \mathrm{c}}$ reduction, are presently regarded as the main criteria for diabetes therapeutics according to the American Diabetes Association/European Association for the Study of Diabetes (ADA/EASD) consensus algorithm for the management of T2DM. ${ }^{4}$ Indeed, in accordance with the ADA/EASD guidelines, in addition to $\mathrm{HbA}_{1 \mathrm{c}}$ efficacy, each new antiglycemic molecule must be assessed and approved for criteria such as tolerance and cardiovascular morbidity and mortality.

At present IDeg is not widely used in clinical practice, but IGla and IDet are routinely used according to the ADA/ EASD efficacy and safety criteria for long-term management of T1DM and T2DM patients. After giving a brief summary of the pharmacokinetic and pharmacodynamic properties of IDeg, this review analyzes the currently available data on the long-term efficacy and safety of IDeg to help promote its optimal use in the treatment and management of T2DM patients.

\section{Degludec insulin: a novel slow human insulin analog}

IDeg is a novel antiglycemic agent belonging to a therapeutic class of slow insulin analogs. These molecules are characterized by delayed absorption and action. The molecular structure of IDeg is similar to that of the human insulin amino acid sequence except for a modified beta chain, ie, deletion of threonine at position 30 and addition of a 16-carbon fatty diacid to lysine at position 29 (Figure 1). ${ }^{5}$

\section{Ultra-flat action profile and low intrapatient variability}

The action of IDeg on the insulin receptor is delayed by two mechanisms. On the one hand, its development is based on the principle of a multi-soluble hexamer. In its pharmaceutical form, before injection, IDeg takes the form of a phenol and zinc formulation containing dihexamers. Once injected, the phenol is quickly eliminated, resulting in formation of multihexamer chains that are released into the subcutaneous tissue. Slow removal of zinc then allows parallel degradation of the multihexamers into monomers, and their gradual entry into the bloodstream. On the other hand, due to the 16-carbon fatty diacid attached at position 29 of the beta chain, the monomers show a high affinity for albumin, further delaying the antiglycemic action. ${ }^{6}$ Noteworthy, IDeg differs from IDet in the fatty acid added at position 29 , ie, its longer carbon chain (16 in IDeg versus 14 in IDet) as well as its binding to lysine via a glutamic acid spacer in IDeg. This dual mechanism confers IDeg with a slower absorption rate than that of IGla and IDet. The half-life and duration of action of IDeg are 25 hours and 42 hours, IDeg. ${ }^{7}$

Studies comparing IDeg with other long-acting insulin analogs have confirmed that IDeg has more stable plasma concentrations. ${ }^{8}$ A pharmacological study by Heise et al showed the intrapatient variability to be four times lower using IDeg than IGla in terms of hypoglycemic effect in T1DM patients. Even more interesting in this study was that the intrapatient variability in the IDeg arm remained stable during 24 hours, while in the IGla arm it

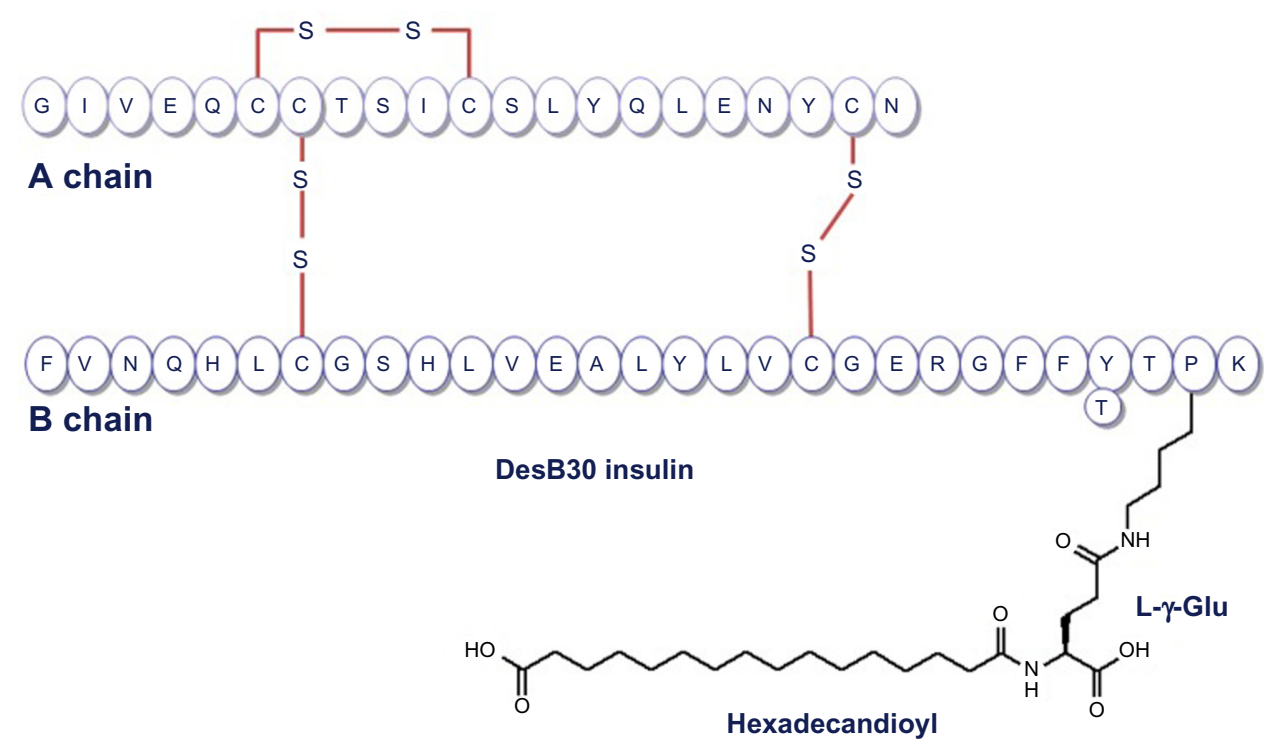

Figure I Structure of insulin degludec DesB30 LysB29 ( $\gamma$-Glu Ne-hexadecandioyl) human insulin. Note: Reprinted by Permission of SAGE. Wakil A., Atkin SL. Ther Adv Endocrinol Metab. 2012;3:55-59. Copyright (C) 2012 SAGE Publications. 
increased significantly 6-8 hours after injection, reaching its maximum between 14 and 16 hours after injection. ${ }^{8}$ In respect to the remarkably flat pharmacokinetic profile of IDeg, several studies have focused on verifying its robustness in the various physiological and pathological contexts commonly encountered in T1DM and T2DM patients. A study of 37 T1DM patients (12 children, 13 adolescents, and 12 adults) confirmed the conservation of this ultra-flat pharmacokinetic profile in children and adolescents. ${ }^{9}$ Another study comparing the pharmacokinetic and pharmacodynamic profiles of IDeg in a group of "young T1DM" (18-35 years) and a group of "older DT1" ( $\geq 65$ years) patients after 6 days of subcutaneous injection reported no change in pharmacokinetic and pharmacodynamic properties of IDeg in the older group of patients. ${ }^{10}$ Two other studies have investigated the pharmacokinetic profile of IDeg in the presence of chronic renal insufficiency and hepatic impairment and confirmed no changes in these subgroups of patients when compared with healthy volunteers. ${ }^{11,12}$

Given the particularly stable plasma concentrations of IDeg, two main hypotheses should be be evaluated: first, whether IDeg could limit the frequency of hypoglycemic events while allowing glycemic control comparable with that obtained using other long-acting human insulin analogs (IGla and IDet); and second, whether its longer duration of action could provide patients with greater flexibility of administration and thus better quality of life. To test these hypotheses, the BEGIN ${ }^{\circledR}$ program was conducted in a large T1DM and T2DM population in the form of several Phase III trials to assess the efficacy and safety of IDeg in various indications and in many regimens (Figure 2). This review focuses on the extensive BEGIN program and other trials that have evaluated IDeg in T2DM patients. Additionally, we review the trials comparing different preparations of IDeg, such as IDegAsp and IDegLira.

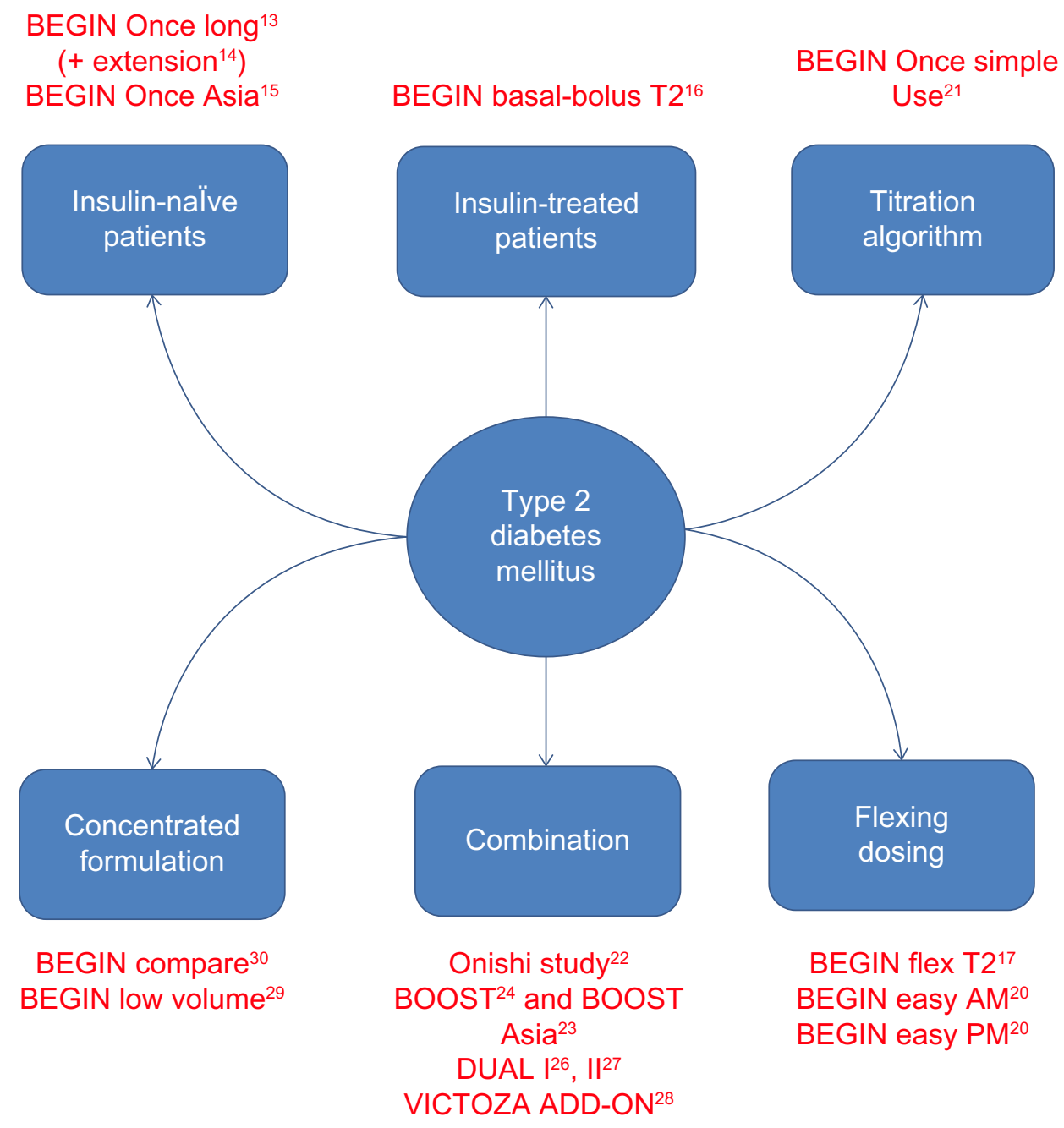

Figure 2 BEGIN program and other studies focusing on insulin degludec in patients with type 2 diabetes mellitus. 


\section{Efficacy of degludec insulin: results of the BEGIN program and other studies}

Studies of the efficacy of IDeg are presented in Figure 2, and are mostly substudies in the BEGIN program. These trials were multicenter, controlled, open-label, randomized, and conducted in a "treat to target" design. The latter confers doses of insulin (basal as well as prandial) systematically adjusted for all patients according to the predetermined scheme built for the study.

The protocols and study populations included in each trial are summarized in Table 1. Inclusion criteria were uncontrolled T2DM and no recent history of severe hypoglycemia. Concomitant oral antidiabetic drug therapy was allowed but differed between studies. The baseline characteristics of the T2DM patients in these therapeutic trials indicate a mean age of 60 years. The duration of T2DM ranged from 8 to 13 years and $\mathrm{HbA}_{1 \mathrm{c}}$ levels were mostly between $8.0 \%$ and $9.0 \%$. Finally, the reported body mass index was around $30 \mathrm{~kg} / \mathrm{m}^{2}$, except in Asian studies where it was lower (approximately $\left.25 \mathrm{~kg} / \mathrm{m}^{2}\right)$.

\section{Degludec insulin once daily alone versus other long-acting insulin analogs in adult T2DM patients Effects on $\mathrm{HbA}_{\mathrm{lc}}$ and fasting prebreakfast glycemia}

The results of the BEGIN studies are detailed in Table 2. The BEGIN Once Long T2 study ${ }^{13}$ investigated insulin-naïve patients who had previously been treated only with oral antidiabetic agents. This 1-year study was extended, ${ }^{14}$ giving 2 years of follow-up, and showed a similar $\mathrm{HbA}_{1 \mathrm{c}}$ reduction in the IDeg arm $(-1.06 \%)$ and IGla arm $(-1.19 \%)$, with an estimated treatment difference (ETD) of 95\% CI $(-0.04$, 0.22 ) between the two groups after 52 weeks of treatment. The fasting prebreakfast glycemia reduction was greater in the IDeg arm than in the IGla arm (ETD IGla-IDeg -0.43 $\mathrm{mmol} / \mathrm{L}[-0.74,-0.13], P=0.005) .{ }^{13}$ Similar results were

Table I Protocols for studies comparing insulin degludec versus a comparator in T2DM patients

\begin{tabular}{|c|c|c|c|c|}
\hline Study & Year & Population & Duration & Patient groups \\
\hline BEGIN Once Long'13 & 2012 & Insulin-naïve T2DM & I years & IDeg $(n=773)$ IGla $(n=257)$ \\
\hline BEGIN Once Long (extension) ${ }^{14}$ & 2013 & Insulin-naïve T2DM & 2 years & \\
\hline Begin Once Asia ${ }^{15}$ & 2013 & Insulin-naïve T2DM & 26 weeks & IDeg $(n=289)$ IGla $(n=146)$ \\
\hline BEGIN Basal-Bolus Type $2^{16}$ & 2012 & $\begin{array}{l}\text { Insulin-treated T2DM } \\
\text { (all regimens accepted) }\end{array}$ & I year & IDeg $(n=744)$ IGla $(n=248)$ \\
\hline BEGIN Flex T2 ${ }^{17}$ & 2013 & $\begin{array}{l}\text { Insulin-naïve T2DM or insulin- } \\
\text { treated T2DM (BI) }\end{array}$ & 26 weeks & $\begin{array}{l}\text { IDeg }(n=228) \\
\text { IDeg }_{\text {Forced-Flex }}(n=229) \\
\text { IGla }(n=230)\end{array}$ \\
\hline BEGIN Easy AM²0 & 2013 & Insulin-naïve T2DM & 26 weeks & $\begin{array}{l}\text { IDeg }_{3 \text { TWAM }}(n=230) \text { IGla OD } \\
(n=230)\end{array}$ \\
\hline BEGIN Easy PM ${ }^{20}$ & 2013 & Insulin-naïve T2DM & 26 weeks & $\begin{array}{l}\operatorname{IDeg}_{\text {ITwPM }}(n=233) \text { IGla OD } \\
(n=234)\end{array}$ \\
\hline BEGIN Low Volume ${ }^{29}$ & 2013 & Insulin-naïve T2DM & 26 weeks & $\begin{array}{l}\text { IDeg } 200 \mathrm{U} / \mathrm{mL}(\mathrm{n}=228) \\
\text { IGla }(\mathrm{n}=228)\end{array}$ \\
\hline BEGIN Compare ${ }^{30}$ & 2014 & Insulin-treated T2DM (BI) & 22 weeks & $\begin{array}{l}\text { IDeg } 200 \mathrm{U} / \mathrm{mL}(\mathrm{n}=186) \\
\text { IDeg } 100 \mathrm{U} / \mathrm{mL}(\mathrm{n}=187)\end{array}$ \\
\hline Onishi et $\mathrm{al}^{22}$ & 2013 & Japanese, insulin-naïve T2DM & 26 weeks & $\begin{array}{l}\text { IDegAsp }(n=\mid 47) \\
\text { IGla }(n=\mid 49)\end{array}$ \\
\hline BOOST Asia ${ }^{23}$ & 2015 & $\begin{array}{l}\text { Asian insulin-treated T2DM } \\
\text { with one BI or more (premixed } \\
\text { or self-mixed insulin) }\end{array}$ & 26 weeks & $\begin{array}{l}\text { IDegAsp twice daily ( } n=282) \\
\text { BIAsp } 30 \text { twice daily }(n=\mid 42)\end{array}$ \\
\hline BOOST $^{24}$ & 2014 & $\begin{array}{l}\text { Insulin-treated T2DM with one } \\
\text { BI or more (premixed or self- } \\
\text { mixed insulin) }\end{array}$ & 26 weeks & $\begin{array}{l}\text { IDegAsp twice daily ( } n=224) \\
\text { BIAsp } 30 \text { twice daily }(n=222)\end{array}$ \\
\hline DUAL- $\|^{27}$ & 2014 & Insulin-treated T2DM (BI) & 26 weeks & IDegLira (n=199) IDeg (n=199) \\
\hline BEGIN Victoza Add-On ${ }^{28}$ & 2014 & $\begin{array}{l}\text { Insulin-treated T2DM from } \\
\text { IDeg arm of [] }\end{array}$ & 26 weeks & $\begin{array}{l}\text { IDeg + liraglutide }(n=88) \\
\text { IDeg + IAsp }(n=89) \text { IDeg }(n=236)\end{array}$ \\
\hline DUAL-126 & 2014 & Insulin-naïve T2DM & 26 weeks & $\begin{array}{l}\text { IDegLira }(n=834) \text { IDeg }(n=4 \mid 4) \\
\text { Liraglutide }(n=4 \mid 5)\end{array}$ \\
\hline
\end{tabular}

Abbreviations: BI, basal insulin; IAsp, aspart insulin; BIAsp 30, biphasic insulin aspart 30/70; IDeg, degludec insulin; IDegAsp, IDegAsp combination; IDeg ${ }_{3 \text { TwAM }}$, degludec

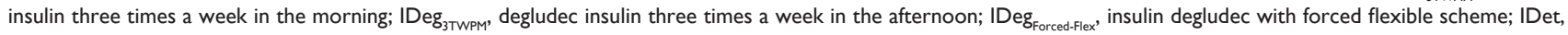
detemir insulin; IGla, glargine insulin; Lira, liraglutide; OD, once daily; T2DM, type 2 diabetes mellitus. 
Table 2 Efficacy of insulin degludec $100 \mathrm{U} / \mathrm{mL}$ versus glargine insulin on $\mathrm{HbA}_{\mathrm{Ic}}$ and fasting blood glucose in patients with type 2 diabetes mellitus

\begin{tabular}{|c|c|c|c|c|c|c|c|}
\hline Study & Arm & $\begin{array}{l}H_{b A} \\
(\% \pm \text { SD) }\end{array}$ & $\begin{array}{l}\text { HbA } A_{l c} \text { reduction } \\
(\% \pm \text { SD) }\end{array}$ & $\begin{array}{l}\text { ETD }(\%) \text { for } \mathrm{HbA}_{\mathrm{lc}} \\
\text { reduction (Cl 95\%) }\end{array}$ & $\begin{array}{l}\text { FBG } \\
(\mathrm{mmol} / \mathrm{L} \pm \mathrm{SD})\end{array}$ & $\begin{array}{l}\text { FBG } \\
\text { reduction } \\
(\mathrm{mmol} / \mathrm{L})\end{array}$ & $\begin{array}{l}\text { ETD (mmol/L) } \\
\text { for FPG [Cl 95\%] }\end{array}$ \\
\hline BEGIN Once & IDeg $(n=773)$ & 7.1 & $-1.06( \pm 1.01)$ & $0.09[-0.04,0.22]$ & 5.9 & $-3.8 \pm 3.04$ & $-0.43[-0.74,-0.13]$ \\
\hline Long $^{13}$ & IGla $(n=257)$ & 7.0 & $-1.19( \pm 0.97)$ & $P=N A$ & 6.4 & $-3.3 \pm 2.87$ & $P=0.005$ \\
\hline BEGIN & IDeg $(n=773)$ & $7.0 \pm 0.9$ & NA & $0.07[-0.07,0.22]$ & $5.56 \pm 1.82$ & -4.17 & $-0.36[-0.67,-0.05]$ \\
\hline $\begin{array}{l}\text { Once Long } \\
\text { (extension) }^{14}\end{array}$ & IGla $(n=257)$ & $6.9 \pm 0.8$ & NA & $P=0.339$ & $5.93 \pm 1.69$ & -3.56 & $P=0.021$ \\
\hline BEGIN Once & IDeg $(n=289)$ & 7.2 & -1.24 & $0.11[-0.03,0.24]$ & 5.5 & 2.88 & $-0.09^{\mathrm{a}}[-0.4 \mathrm{I}, 0.23]$ \\
\hline Asia ${ }^{15}$ & IGla $(n=\mid 46)$ & 7.1 & -1.35 & $P=N A$ & 5.7 & 2.97 & $P=0.59$ \\
\hline BEGIN & IDeg $(n=744)$ & NA & -1.10 & & NA & -2.3 & $-0.29[-0.65,0.06]$ \\
\hline \multirow[t]{2}{*}{ Type $2^{16}$} & IGla (n=248) & NA & -1.18 & $\begin{array}{l}0.08[-0.05,0.2 I] \\
P=\mathrm{NA}\end{array}$ & NA & -2.0 & $P=0.1075$ \\
\hline & IDeg $(n=226)$ & NA & -1.07 & $\begin{array}{l}\text { IDeg }_{\text {Forced-Flex }} \text { versus } \\
\text { IDeg NA }\end{array}$ & 5.8 & NA & $\begin{array}{l}\text { IDeg }_{\text {Forced-Flex }} \text { versus } \\
\text { IDeg } \\
-0.05[0.45,0.25] \\
P=\text { NA }\end{array}$ \\
\hline \multirow[t]{2}{*}{$\begin{array}{l}\text { BEGIN Flex } \\
\mathrm{T}^{17}\end{array}$} & $\begin{array}{l}\text { IDeg }_{\text {Forced-Flex }} \\
(n=230)\end{array}$ & NA & -1.28 & $\begin{array}{l}\text { IDeg }_{\text {Forced-Flex }} \text { versus } \\
\text { IGla } \\
0.04[-0.12,0.20]\end{array}$ & 5.8 & NA & $\begin{array}{l}\text { IDeg }_{\text {Forced-Flex }} \text { versus } \\
\text { IGla } \\
-0.42[-0.82,-0.02]\end{array}$ \\
\hline & IGla (n=229) & NA & -1.26 & & 6.2 & NA & $P=0.04$ \\
\hline
\end{tabular}

Note: ${ }^{a} E T D(\mathrm{mmol} / \mathrm{L})$ for FPG in favor of IGla, mean \pm SD.

Abbreviations: $\mathrm{Cl}$, confidence interval; ETD, estimated treatment difference; FPG, fasting plasma glucose; IDeg, insulin degludec; IDeg ${ }_{\text {Forced-Flex }}$ insulin degludec with forced flexible scheme; IDet, detemir insulin; IGla, glargine insulin; NA, not available; SD, standard deviation.

found in the extension phase,${ }^{14}$ ie, no significant difference in $\mathrm{HbA}_{1 \mathrm{c}}$ reduction between the two arms (ETD IGla-IDeg to $0.07 \%(-0.07,0.22 ; P=0.339)$ and a greater $\mathrm{FPG}$ reduction in the IDeg arm versus the IGla arm (ETD IGla-IDeg to $-0.36 \%$ $[-0.67,-0.05], P=0.021)$. When comparing the BEGIN Once Long studies, the BEGIN Once Long Asia study also compared IDeg versus IGla in insulin-naïve patients, but for a shorter 26-week study period. ${ }^{15}$ After 26 weeks of follow-up, both groups showed a comparable reduction in $\mathrm{HbA}_{1 \mathrm{c}}$, with an ETD at $0.11 \%(-0.03,0.24)$. However, reduction of fasting plasma glucose was slightly higher in the IGla arm although the ETD was not statistically significant (ETD IDeg - IGla, $-0.09 \mathrm{mmol} / \mathrm{L}[-0.41,0.23], P=0.59) .{ }^{15}$

The BEGIN Basal-Bolus T2 study ${ }^{16}$ included T2DM patients who had been treated with insulin for more than 3 months prior to enrollment. The insulin therapy had been delivered as either once-daily basal insulin or in an intensified dosing pattern of basal bolus. There was a similar statistically significant $\mathrm{HbA}_{1 \mathrm{c}}$ reduction in the IDeg group $(-1.10 \%)$ and the IGla group $(-1.18 \%)$ with an ETD of $0.08 \%(-0.05,0.21)$. However, there was a greater (albeit not statistically significant) reduction of fasting plasma glucose (ETD IGla - IDeg, $-0.29[-0.65,0.06], P=0.1075)$ in the IDeg group. ${ }^{16}$

Finally, the BEGIN Flex T2 study ${ }^{17}$ evaluated the flexibility of IDeg administration in insulin-naïve T2DM patients versus those treated with basal insulin therapy. The protocol involved randomizing patients into three treatment arms, ie, IGla, IDeg, and IDeg Forced-Flex IDeg $_{\text {Foreed-Flex }}$ was a prespecified, rotating morning and evening dosing schedule that created an 8-40-hour interval between doses. The study showed similar efficacy with regard to reduction of $\mathrm{HbA}_{1 \mathrm{c}}$

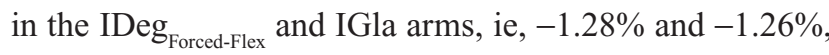
respectively (ETD IGla - IDeg Fored-Flex $0.04[-0.12,0.20]$ ). Surprisingly, in this study, IDeg seemed lower in efficacy compared with the other two arms, with an $\mathrm{HbA}_{1 \mathrm{c}}$ reduction of $-1.07 \%$. The study did not include a statistical comparison between IDeg and the two other arms in terms of $\mathrm{HbA}_{1 \mathrm{c}}$ reduction. However, final difference in $\mathrm{HbA}_{1 \mathrm{c}}$ between the IDeg and IDeg $_{\text {Forced-Flex }}$ arms was not significant (ETD IDeg - IDeg $\left._{\text {Forced-Flex }}-0.13 \%[-0.29,0.03]\right)$.

\section{Degludec insulin and hypoglycemia in T2DM patients}

The results of the studies in the BEGIN program are detailed in Table 3. In respect to the overall hypoglycemia rate, only the BEGIN Basal-Bolus T2 study ${ }^{16}$ showed a slightly significant reduction in hypoglycemia in T2DM patients $(-18 \%$, $P=0.0359$ ). The results of the BEGIN Once Long ${ }^{13,14}$ and BEGIN Once Asia ${ }^{16}$ studies showed a similar (but not statistically significant) reduction of $18 \%$ and $16 \%$ at 1 and 2 years 
Table 3 Efficacy of insulin degludec $100 \mathrm{U} / \mathrm{mL}$ versus glargine insulin on hypoglycemia events in patients with type 2 diabetes mellitus

\begin{tabular}{|c|c|c|c|c|c|c|c|}
\hline Study & Arm & $\begin{array}{l}\text { Overall } \\
\text { hypoglycemia } \\
\text { (episodes per } \\
\text { patient/year) }\end{array}$ & $\begin{array}{l}\text { Estimate ratio } \\
\text { of overall } \\
\text { hypoglycemia } \\
\text { [Cl 95\%] }\end{array}$ & $\begin{array}{l}\text { Severe } \\
\text { hypoglycemia } \\
\text { (episode per } \\
\text { patient/year) }\end{array}$ & $\begin{array}{l}\text { Estimate ratio } \\
\text { of severe } \\
\text { hypoglycemia } \\
\text { [Cl 95\%] }\end{array}$ & $\begin{array}{l}\text { Nocturnal } \\
\text { hypoglycemia } \\
\text { (episodes per } \\
\text { patient/year) }\end{array}$ & $\begin{array}{l}\text { Estimate ratio } \\
\text { of nocturnal } \\
\text { hypoglycemia } \\
\text { [Cl 95\%] }\end{array}$ \\
\hline BEGIN Once & IDeg $(n=773)$ & 1.52 & $0.82[0.64-1.04]$ & 0.003 & $0.14[0.03-0.70]$ & 0.25 & $0.64[0.42-0.98]$ \\
\hline \multirow[t]{2}{*}{ Long $^{13}$} & & & $P=0.106$ & & $P=0.017$ & & $P=0.038$ \\
\hline & IGla $(n=257)$ & 1.85 & & 0.023 & & 0.39 & \\
\hline BEGIN Once & IDeg $(n=773)$ & 1.72 & $0.84[0.68-1.04]$ & 0.006 & $0.31[0.11-0.85]$ & 0.27 & $0.57[0.40-0.81]$ \\
\hline $\begin{array}{l}\text { Long } \\
\text { (extension) }^{14}\end{array}$ & IGla (n=257) & 2.05 & $P=0.115$ & 0.021 & $P=0.023$ & 0.46 & $P=0.002$ \\
\hline BEGIN Once & IDeg $(n=289)$ & 3.0 & $0.82[0.60-1.1 \mathrm{I}]$ & 0 & NA & 0.8 & $0.62[0.38-1.04]$ \\
\hline Asia $^{15}$ & IGla $(n=\mid 46)$ & 3.7 & $P=0.20$ & I episode & & 1.2 & $P=0.07$ \\
\hline BEGIN Basal- & IDeg $(n=744)$ & 11.09 & $0.82[0.69-0.99]$ & 0.06 & NA & 1.39 & $0.75[0.58-0.99]$ \\
\hline \multirow[t]{2}{*}{ Bolus Type $2^{16}$} & & & $P=0.0359$ & & & & $P=0.0399$ \\
\hline & IGla $(n=248)$ & 13.63 & & 0.05 & & 1.84 & \\
\hline \multirow[t]{3}{*}{$\begin{array}{l}\text { BEGIN Flex } \\
\mathrm{T} 2^{17}\end{array}$} & IDeg $(n=226)$ & 3.6 & $\begin{array}{l}\text { IDeg }_{\text {Forced-Flex }} / \text { IDeg } \\
1.10[0.79-1.52]\end{array}$ & NA & $\begin{array}{l}\text { Two episodes } \\
\text { in each group }\end{array}$ & 0.6 & $\begin{array}{l}\mathrm{IDeg}_{\text {Forced-Flex }} / \mathrm{IDeg} \\
\mathrm{I} .18[0.66,2.12]\end{array}$ \\
\hline & $\begin{array}{l}\text { IDeg }_{\text {Forced-Flex }} \\
(\mathrm{n}=230)\end{array}$ & 3.6 & $\begin{array}{l}\mathrm{IDeg}_{\text {Forced-Flex }} / \mathrm{IGla} \\
\mathrm{I} .03[0.75, \mathrm{I} .40]\end{array}$ & NA & & 0.6 & $\begin{array}{l}\mathrm{IDeg}_{\text {Forced-Flex }} / \mathrm{IGla} \\
0.77[0.44 ; 1.35]\end{array}$ \\
\hline & IGla (n=229) & 3.5 & NS & NA & & 0.8 & $P=\mathrm{NS}$ \\
\hline
\end{tabular}

Abbreviations: IDeg, insulin degludec; IDeg ${ }_{\text {Forced-Flex }}$ insulin degludec with forced flexible scheme; IDet, detemir insulin; IGla, glargine insulin; NA, not available; NS, not statistically significant.

of follow-up in the IDeg group $(P=0.106$ and $P=0.115$, respectively) for the BEGIN Once Long study and $18 \%$ at 26 weeks of follow-up ( $P=0.20)$ for the BEGIN Once Asia study.

IDeg achieved a significant reduction in nocturnal hypoglycemia in insulin-naïve patients (from $-36 \%$ to $-43 \%$ ) in the BEGIN Once Long study at 1 and 2 years $(P=0.038$ and $P=0.002$, respectively $)^{13,14}$ and in T2DM patients treated with basal-bolus in the BEGIN basal-bolus T2 study $(-25 \%$, $P=0.0399) .{ }^{16}$

Finally, on the criterion of severe hypoglycemia, only the BEGIN Once Long study, in insulin-naïve T2DM patients, showed a lower rate of severe hypoglycemia in the IDeg versus IGla arm, ie, $0.14(P=0.017)$ versus $0.31(P=0.023)$ at 1 and 2 years, respectively. ${ }^{13,14}$ However, the number of events was very low in both groups (seven episodes in 8/257 patients in the IGla group and six episodes in $7 / 766$ patients in the IDeg group) leading to caution in the interpretation of these ratios. Other studies have found comparable data with regard to the severe hypoglycemia rate in IDeg and IGla groups.

More recently, Hollander et $\mathrm{al}^{18}$ published their latest results for the BEGIN Basal-bolus T2 cohort. After 78 weeks of follow-up, the overall rate of hypoglycemia was $24 \%$ lower $(P=0.011)$ and the rate of nocturnal hypoglycemia was $31 \%$ lower $(P=0.016)$ in the IDeg group, with similar glycemic control in both groups.

A recent meta-analysis ${ }^{19}$ of five studies in T2DM showed higher efficacy of IDeg versus IGla in reduction of overall hypoglycemia (estimated rate ratio [ERR] 0.83 [0.74-0.94]) and nocturnal hypoglycemia (ERR 0.68 [0.57-0.82]). However, comparable efficacy was reported for both antiglycemic agents in reduction of severe hypoglycemia (ERR 0.81 [0.42-1.56]). Finally, the same meta-analysis reported a statistically significant reduction in overall $(-25 \%)$ and nocturnal $(-38 \%)$ hypoglycemia rates during the maintenance period. These data suggest a long-term beneficial effect of IDeg after its optimal dose is achieved.

\section{Towards a therapeutic regimen with IDeg three times a week?}

The ultra-long duration of action of IDeg allows longer injection intervals while maintaining consistent glycemic control, so it might be beneficial in specific patient populations, especially insulin-naïve T2DM patients. BEGIN Easy AM/BEGIN Easy PM $^{20}$ studied such an hypothesis by comparing administration of IDeg three times a week (3TW) in the morning (AM) and evening (PM), respectively, with administration of IGla once daily. BEGIN Easy AM included 460 patients in two arms, ie, $\operatorname{IDeg}_{\text {зTWAM }}(n=230)$ and IGla once daily $(n=230)$. The BEGIN Easy PM study included 467 patients in two arms, ie, $\operatorname{IDeg}_{\text {3TwPM}},(n=233)$ and IGla once daily $(n=234)$. The duration of the studies was 26 weeks in both cases. Unfortunately, on the criterion of $\mathrm{HbA}_{1 \mathrm{c}}$, noninferiority of IDeg ${ }_{3 \mathrm{TW}}$ was not shown in either of the two trials, with an ETD of $0.34 \%(0.18,0.51)$ in BEGIN Easy AM and $0.26 \%(0.11,0.41)$ in BEGIN Easy PM. In 
addition, the overall hypoglycemic risk was increased in the IDeg $_{\text {3тพPM }}$ arm versus the IGla once daily arm, with an ERR of $1.58(1.03,2.43)$, and the rate of nocturnal confirmed hypoglycemia was higher in the IDeg $_{3 \text { TwAM }}$ group than in the IGla once daily group (ERR $2.12(1.08,4.16)$. The authors concluded that they did not recommend use of IDeg $_{3 \mathrm{TW}}$ in the morning or evening for insulin-naïve T2DM patients.

\section{Insulin degludec: which titration algorithm is the most effective?}

The ultra-long duration of action of IDeg, ie, more than 24 hours, might not be relevant in dose adjustment from fasting prebreakfast glycemia, which is commonly used for titration of other long-acting analogs. The BEGIN Once Single Use ${ }^{21}$ study aimed to identify the best titration modality for adjusting the IDeg dose, using a "simple" algorithm allowing dose adjustment according to a prebreakfast selfmeasured plasma glucose versus a "step-wise" algorithm allowing dose adjustment according to the lowest prebreakfast self-measured plasma glucose in the last 3 days. Patients $(n=222)$ were randomly assigned into two arms, ie, IDeg $_{\text {simple }}$

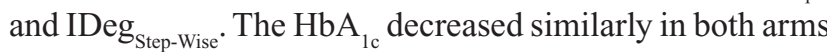
$\left(-1.09 \%\right.$ in IDeg simple $_{\text {versus }-0.93 \%}$ in IDeg $\left._{\text {Step-Wise }}\right)$ with an ETD of $-0.16 \%(-0.39,0.07)$. The overall and nocturnal hypoglycemia rates were not significantly different. The authors concluded that both algorithms showed comparable effectiveness and tolerance, suggesting the possibility of using the two algorithms according to patient preference.

\section{Other forms of insulin degludec for T2DM patients}

Other forms of IDeg have been developed for use in T2DM patients, including IDeg-IAsp and IDeg-liraglutide (IDeg-Lira) preparations; the former is a soluble coformulation of IDeg and IAsp (70\% IDeg and 30\% IAsp). In a study by Onishi et al, ${ }^{22}$ IDegAsp was compared with IGla alone. After 26 weeks, mean $\mathrm{HbA}_{1 \mathrm{c}}$ was lower in the IDegAsp arm $(7.0 \%)$ than in the IGla arm (7.3\%), with an ETD (IDegAsp - IGla) of $-0.28 \%(-0.46,-0.10, P<0.01)$. Further, IDegAsp was associated with lower rates of overall and nocturnal hypoglycemia versus IGla, but the ERRs of $0.73(0.50,1.08)$ and $0.75(0.34,1.64)$ were not statistically significant.

In the BOOST trials, ${ }^{23,24}$ IDegAsp was compared with premixed biphasic insulin aspart 30, each administered twice daily. Both studies showed comparable $\mathrm{HbA}_{1 \mathrm{c}}$ reduction, with superior reduction in fasting plasma glucose for IDegAsp (ETD $-1.06 \mathrm{mmol} / \mathrm{L}[-1.43,-0.70], P<0.001$ in the Kaneko et al trial ${ }^{23}$ and $-1.14 \mathrm{mmol} / \mathrm{L}[-1.53,-0.76]$,
$P<0.001)$ in the Fulcher et al trial ${ }^{24}$ with a lower total daily insulin dose in IDegAsp versus biphasic insulin aspart 30. In the former trial, rates of overall and severe hypoglycemia were similar in both groups, while the rate of confirmed nocturnal hypoglycemia was lower with IDegAsp (ERR $0.67[0.43,1.06])$, but not statistically significant. In the trial by Fulcher et al, rates of overall and confirmed nocturnal hypoglycemia were lower in the IDegAsp group (ERR 0.68 [0.52, 0.89] $P=0.0049$ and 0.27 [0.18, 0.41], $P<0.0001$, respectively). In the maintenance period, rates of severe hypoglycemia were also lower for IDegAsp $(P=0.04)$, with one episode in the IDegAsp group versus 13 episodes in the biphasic insulin aspart 30 group. These two studies suggest an equivalent efficacy of IDegAsp versus biphasic insulin aspart 30 for $\mathrm{HbA}_{1 \mathrm{c}}$ reduction, with a decreased risk of overall and nocturnal hypoglycemia and probably a reduction of severe hypoglycemia in the maintenance period.

The ADA and EASD recently approved the combination of basal insulin and a GLP-1 receptor agonist. ${ }^{4}$ IDegLira, a novel combination of basal IDeg and the long-acting GLP-1 analog liraglutide, was then developed for the treatment of T2DM patients as a once-daily, single subcutaneous injection. The pharmacological rationale for use of this combination is that lower fasting blood glucose levels can be obtained using IDeg and liraglutide, while liraglutide can also modestly reduce post-prandial glucose excursions. ${ }^{25}$ The DUAL-I showed noninferiority of IDegLira versus IDeg alone, with an ETD of $-0.47 \%(-0.58,-0.36, P<0.0001)$. The same trial showed the superiority of IDegLira versus liraglutide (ETD $-0.64 \%(-0.75,-0.53, P<0.0001) .{ }^{26}$ The DUAL-2 trial showed the superiority of IDegLira versus IDeg alone in terms of $\mathrm{HbA}_{1 \mathrm{c}}$ reduction $(-1.9 \%$ in the IDegLira arm versus $-0.9 \%$ in the IDeg arm; ETD $-1.1 \%$ $[-1.3,-0.8], P<0.0001)$ and mean weight reduction. ${ }^{27}$ However, the hypoglycemia rate was comparable in both groups.

Finally, the BEGIN Victoza Add-On study ${ }^{28}$ compared IDeg + IAsp versus IDeg + liraglutide in a T2DM population from the BEGIN Once Long extension cohort. ${ }^{14}$ Patients were randomized to IDeg + liraglutide and IDegAsp if the target $\mathrm{HbA}_{1 \mathrm{c}}(\geq 7.0 \%)$ was not reached at 104 weeks. If their $\mathrm{HbA}_{1 \mathrm{c}}$ was $<7.0 \%$, patients continued IDeg in a third nonrandomized arm. The results showed than IDeg + liraglutide $(-0.74 \%)$ reduced $\mathrm{HbA}_{1 \mathrm{c}}$ significantly more than IDeg + IAsp $(-0.39 \%)$, with an ETD of $-0.32 \%(-0.53,-0.12, P=0.0024)$. Further, patients on IDeg + liraglutide had significantly less overall and nocturnal hypoglycemia, and significantly greater weight loss $(-2.8 \mathrm{~kg})$ versus patients on IDeg + IAsp (+0.9 kg) 
with an ETD (IDeg + liraglutide - IDeg + IAsp) of $-3.75 \mathrm{~kg}$ $(-4.70,-2.79, P<0.0001)$. This study suggested that adding a long-acting GLP-1 analog such as liraglutide may be superior to adding a single daily dose of IAsp in the event of failure of IDeg + metformin to achieve $\mathrm{HbA}_{1 \mathrm{c}}$ reduction and weight loss, as well as in prevention of hypoglycemic events. ${ }^{28}$

A more concentrated form of IDeg $(200 \mathrm{U} / \mathrm{mL})$ has been also developed and tested in two studies, ie, BEGIN Low Volume ${ }^{29}$ and BEGIN Compare. ${ }^{30}$ BEGIN Low Volume compared IDeg (200 IU/mL) versus IGla and reported results similar to those of other trials in insulin-naïve T2DM patients, with equal efficacy in terms of $\mathrm{HbA}_{1 \mathrm{c}}$ reduction and a comparable hypoglycemia rate. ${ }^{29}$ The BEGIN Compare study compared IDeg $200 \mathrm{IU} / \mathrm{mL}$ with IDeg $100 \mathrm{IU} / \mathrm{mL}$, and the results showed comparable efficacy between the groups with regard to glycemic control and hypoglycemia rates. ${ }^{30}$

\section{Insulin degludec and quality of life in T2DM patients}

In addition to assessment of efficacy and safety criteria, there are at least two hypotheses concerning assessment of quality of life related to the use of an antiglycemic agent. T2DM patients treated with IDeg may feel less stress than those treated with antiglycemic agents administered on a strict schedule. Moreover, the significant reduction in nocturnal hypoglycemia rate achieved by IDeg could be a factor in improving quality of life in T2DM patients. It is known that hypoglycemia-related anxiety is associated with deterioration of quality of life in patients with diabetes. ${ }^{31}$ A recent meta-analysis ${ }^{32}$ addressed this issue using the Short-Form 36 questionnaire filled in by patients (T2DM patients in five trials and T1DM patients in one trial. These results were then processed and converted into a EuroQol-5D score. The metaanalysis concluded that there was a moderate but significant improvement in quality of life in patients treated with IDeg when compared with those treated with IGla. This improvement was independent of the flexibility of administration, ie, IDeg was injected at a fixed time once daily. Further studies are needed to better understand the benefits of IDeg on quality of life in T2DM patients.

\section{Insulin degludec safety and adverse effects General adverse effects}

Several studies have evaluated the safety of IDeg. To date, no study has shown either more or serious adverse events in patients treated with IDeg compared with those treated with IGla. Moreover, according to this review, the proportion of patient drop outs was not different among studies. In terms of the IDeg doses used, tests in T2DM patients showed no obvious difference between insulin doses in the IDeg and IGla groups. According to the literature, comparable weight gain results were obtained in T2DM patients treated with IDeg compared with those treated with IGla. It is worth mentioning that immunological studies have found insignificant traces of anti-degludec antibody in T2DM patients. ${ }^{13,17}$

As a result, the currently available data on use of IDeg in daily clinical practice seem reassuring. However, the limitations of trial duration and sample size in the current literature on the safety of IDeg preclude any results being able to be considered conclusive. Larger and longer duration randomized prospective trials on IDeg-related adverse events and serious adverse events are needed to obtain evidence-based and conclusive data. Two important criteria regarding the safety of IDeg need to be further evaluated, ie, cardiovascular safety and risk of neoplasia.

\section{Cardiovascular safety}

This systemic review highlights the limitations of the available published trials, ie, short observation periods and small sample sizes. Consequently, there are no current conclusive data on the cardiovascular safety of IDeg. However, a 2012 US Food and Drug Administration study of randomized Phase III trials in T1DM and T2DM patients reported a potential cardiovascular risk associated with IDeg. Indeed, in most of the trials comparing IDeg/IDegAsp with a comparator arm, the incidence of cardiovascular events was estimated according to composite criteria of MACE (major adverse cardiovascular events) and MACE+. The latter criterion estimated the occurrence of events during follow-up, ie, acute coronary syndrome, including unstable angina and myocardial infarction, stroke, and cardiovascular death. The definition of cardiovascular events according to the MACE criterion was stricter than that by MACE+ and excluded unstable angina. All events occurring 7 days after cessation of treatment were censored. According to the MACE+ criterion, 95/5,794 events in the IDeg/IDegAsp group versus 37/3,461 in the comparator group were observed (hazard ratio 1.30; $95 \%$ confidence interval $0.88-1.93$ ). According to the MACE criterion, there were 70/5,794 events in the IDeg/IDegAsp group versus 21/3,461 in the comparator group (hazard ratio $1.67 ; 95 \%$ confidence interval 1.01-2.75). The number of cardiovascular events according to the MACE criterion was then more statistically significant in IDeg/IDegAsp group.

Given the above data, although limited and not representing those in the general diabetes patient population, the US 
Food and Drug Administration has delayed the marketing authorization for IDeg, and requested additional prospective randomized studies on the cardiovascular safety of IDeg. In contrast, the European Medicines Agency and other national health authorities have granted marketing authorization for IDeg. Such divergence in marketing authorization approvals has generated debate on the potential cardiovascular risk of IDeg. To date, there is no relevant evidence-based rationale to explain any potential IDeg-associated cardiovascular risk. The DEVOTE (NCT 01959529) trial is in progress, and is aiming to enroll 7,500 T2DM subjects at high cardiovascular risk (age $\geq 50$ years with a history of cardiovascular disease or diabetic nephropathy or age $\geq 60$ years with cardiovascular risk factors) in order to evaluate such an hypothesis. The results of this trial are expected to be available in 2018. However, according to Novo Nordisk, it seems that the US Food and Drug Administration has accepted a resubmitted marketing authorization application based on interim analysis of data from the DEVOTE study.

\section{Risk of neoplasia}

In 2009, some cohort studies ${ }^{33,34}$ raised the issue of a potentially increased risk of cancer in T2DM patients treated with IGla. To date, no study has demonstrated the increased risk of cancer in T2DM patients on IGla therapy. ${ }^{35}$ The suspicion of a potential risk of neoplasia in T2DM patients treated with IGla has been explained based on the theoretical capacity of IGla to have insulin-like growth factor 1 (IGF-1)-like activity after its interaction with the IGF-1 receptor. Indeed, several studies have shown a greater affinity of IGla compared with that of human insulin for the IGF-1 receptor in vitro. ${ }^{36}$ This greater affinity can be explained by the addition of arginine residues at positions 31 and 32 of the beta chain, thus suggesting an increased risk of cancer in patients treated with IGla. In contrast, in vivo metabolism of IGla in blood shows low mitogenic activity due to the low affinity of its primary metabolite for the IGF-1 receptor. ${ }^{37}$ In respect to IDeg, data from the study by Nishimura et al showed a lower affinity of IDeg for the IGF-1 receptor in comparison with that of human insulin. ${ }^{38}$ These results theoretically suggest the absence of increased risk in patients treated with IDeg. However, clinically, the duration of this study does not allow an evidencebased conclusion to be reached. The results of the BEGIN Once Long trial in insulin-naïve T2DM patients followed for 1 year showed a very low rate of cancer in the IDeg and IGla groups $(1.0 \%$ [8/766] in the IDeg group and 0.8\% [2/257] in the IGla group). ${ }^{13} \mathrm{~A}$ prospective cohort with long-term follow-up is therefore needed to better assess this risk.

\section{Conclusion}

In conclusion, the study results suggest that IDeg provides glycemic control and reduction of nocturnal hypoglycemia comparable with that achieved by other long-acting analogs (IGla and IDet) in patients with T2DM. The rate of severe hypoglycemia also seems to be reduced when using IDeg therapy; however, long-term follow-up is warranted for monitoring of possible but relatively infrequent adverse events. On the other hand, a 2012 US Food and Drug Administration study revealed a potential IDeg-associated cardiovascular risk. Future prospective evaluation of large cohorts of T2DM patients treated with IDeg, with long-term follow-up, can provide more relevant information on the safety of IDeg therapy.

\section{Disclosure}

We declare that there is no conflict of interest that could be perceived as prejudicing the impartiality of this work.

\section{References}

1. Lepore M, Pampanelli S, Fanelli C, et al. Pharmacokinetics and pharmacodynamics of subcutaneous injection of long-acting human insulin analog glargine, NPH insulin, and ultralente human insulin and continuous subcutaneous infusion of insulin lispro. Diabetes. 2000;49:2142-2148.

2. Heise T, Tack CJ, Cuddihy R, et al. A new-generation ultra-long-acting basal insulin with a bolus boost compared with insulin glargine in insulin-naive people with type 2 diabetes: a randomized, controlled trial. Diabetes Care. 2011;34:669-674.

3. Horvath K, Jeitler K, Berghold A, et al. Long-acting insulin analogues versus NPH insulin (human isophane insulin) for type 2 diabetes mellitus. Cochrane Database Syst Rev. 2007;2:CD005613.

4. Inzucchi, Silvio E., Richard M. Bergenstal, John B. Buse, et al. 2015 Management of Hyperglycemia in Type 2 Diabetes, 2015: A PatientCentered Approach: Update to a Position Statement of the American Diabetes Association and the European Association for the Study of Diabetes. Diabetes Care. 38(1):140-149.

5. Wakil A, Atkin SL. Efficacy and safety of ultra-long-acting insulin degludec. Ther Adv Endocrinol Metab. 2012;3:55-59.

6. Jonassen I, Havelund S, Hoeg-Jensen T, Steensgaard DB, Wahlund P-O, Ribel U. Design of the novel protraction mechanism of insulin degludec, an ultra-long-acting basal insulin. Pharm Res. 2012;29:2104-2114.

7. Haahr H, Heise T. A review of the pharmacological properties of insulin degludec and their clinical relevance. Clin Pharmacokinet. 2014;53:787-800.

8. Heise T, Hermanski L, Nosek L, Feldman A, Rasmussen S, Haahr H. Insulin degludec: four times lower pharmacodynamic variability than insulin glargine under steady-state conditions in type 1 diabetes. Diabetes Obes Metab. 2012;14:859-864.

9. Biester T, Blaesig S, Remus K, et al. Insulin degludec's ultra-long pharmacokinetic properties observed in adults are retained in children and adolescents with type 1 diabetes: insulin degludec in children/ adolescents. Pediatr Diabetes. 2014;15:27-33.

10. Korsatko S, Deller S, Mader JK, et al. Ultra-long pharmacokinetic properties of insulin degludec are comparable in elderly subjects and younger adults with type 1 diabetes mellitus. Drugs Aging. 2014;31:47-53.

11. Kiss I, Arold G, Roepstorff C, Bøttcher SG, Klim S, Haahr H. Insulin degludec: pharmacokinetics in patients with renal impairment. Clin Pharmacokinet. 2014;53:175-183. 
12. Kupčová V, Arold G, Roepstorff C, Højbjerre M, Klim S, Haahr H. Insulin degludec: pharmacokinetic properties in subjects with hepatic impairment. Clin Drug Investig. 2014;34:127-133.

13. Zinman B, Philis-Tsimikas A, Cariou B, et al. Insulin degludec versus insulin glargine in insulin-naive patients with type 2 diabetes: a 1-year, randomized, treat-to-target trial (BEGIN Once Long). Diabetes Care. 2012;35:2464-2471.

14. Rodbard HW, Cariou B, Zinman B, et al. Comparison of insulin degludec with insulin glargine in insulin-naive subjects with type 2 diabetes: a 2 -year randomized, treat-to-target trial. Diabet Med. 2013;30:1298-1304.

15. Onishi Y, Iwamoto Y, Yoo SJ, Clauson P, Tamer SC, Park S. Insulin degludec compared with insulin glargine in insulin-naïve patients with type 2 diabetes: a 26-week, randomized, controlled, Pan-Asian, treatto-target trial. J Diabetes Investig. 2013;4:605-612.

16. Garber AJ, King AB, Prato SD, et al. Insulin degludec, an ultralongacting basal insulin, versus insulin glargine in basal-bolus treatment with mealtime insulin aspart in type 2 diabetes (BEGIN Basal-Bolus Type 2): a phase 3, randomised, open-label, treat-to-target noninferiority trial. Lancet. 2012;379:1498-1507.

17. Meneghini L, Atkin SL, Gough SCL, et al. The efficacy and safety of insulin degludec given in variable once-daily dosing intervals compared with insulin glargine and insulin degludec dosed at the same time daily: a 26-week, randomized, open-label, parallel-group, treat-to-target trial in individuals with type 2 diabetes. Diabetes Care. 2013;36:858-864.

18. Hollander $\mathrm{P}$, King AB, Del Prato S, et al. Insulin degludec improves long-term glycaemic control similarly to insulin glargine but with fewer hypoglycaemic episodes in patients with advanced type 2 diabetes on basal-bolus insulin therapy. Diabetes Obes Metab. 2015;17: 202-206.

19. Ratner RE, Gough SCL, Mathieu C, et al. Hypoglycaemia risk with insulin degludec compared with insulin glargine in type 2 and type 1 diabetes: a pre-planned meta-analysis of phase 3 trials. Diabetes Obes Metab. 2013;15:175-184.

20. Zinman B, DeVries JH, Bode B, et al. Efficacy and safety of insulin degludec three times a week versus insulin glargine once a day in insulinnaive patients with type 2 diabetes: results of two phase 3, 26 week, randomised, open-label, treat-to-target, non-inferiority trials. Lancet Diabetes Endocrinol. 2013;1:123-131.

21. Philis-Tsimikas A, Brod M, Niemeyer M, Ocampo Francisco AM, Rothman J. Insulin degludec once-daily in type 2 diabetes: simple or step-wise titration (BEGIN: Once Simple Use). Adv Ther. 2013;30: 607-622.

22. Onishi Y, Ono Y, Rabøl R, Endahl L, Nakamura S. Superior glycaemic control with once-daily insulin degludec/insulin aspart versus insulin glargine in Japanese adults with type 2 diabetes inadequately controlled with oral drugs: a randomized, controlled phase 3 trial. Diabetes Obes Metab. 2013;15:826-832.

23. Kaneko S, Chow F, Choi DS, et al. Insulin degludec/insulin aspart versus biphasic insulin aspart 30 in Asian patients with type 2 diabetes inadequately controlled on basal or pre-/self-mixed insulin: a 26-week, randomised, treat-to-target trial. Diabetes Res Clin Pract. 2015;107:139-147.

24. Fulcher GR, Christiansen JS, Bantwal G, et al. Comparison of insulin degludec/insulin aspart and biphasic insulin aspart 30 in uncontrolled, insulin-treated type 2 diabetes: a Phase 3a, randomized, treat-to-target trial. Diabetes Care. 2014;37:2084-2090.
25. Meier JJ. GLP-1 receptor agonists for individualized treatment of type 2 diabetes mellitus. Nat Rev Endocrinol. 2012;8:728-742.

26. Gough SC, Bode B, Woo V, et al. Efficacy and safety of a fixedratio combination of insulin degludec and liraglutide (IDegLira) compared with its components given alone: results of a phase 3, open-label, randomised, 26-week, treat-to-target trial in insulin-naive patients with type 2 diabetes. Lancet Diabetes Endocrinol. 2014;2: 885-893.

27. Buse JB, Vilsboll T, Thurman J, et al. Contribution of liraglutide in the fixed-ratio combination of insulin degludec and liraglutide (IDegLira). Diabetes Care. 2014;37:2926-2933.

28. Mathieu C, Rodbard HW, Cariou B, et al. A comparison of adding liraglutide versus a single daily dose of insulin aspart to insulin degludec in subjects with type 2 diabetes (BEGIN: VICTOZA ADD-ON). Diabetes Obes Metab. 2014;16:636-644.

29. Gough SCL, Bhargava A, Jain R, Mersebach H, Rasmussen S, Bergenstal RM. Low-volume insulin degludec 200 units/mL once daily improves glycemic control similarly to insulin glargine with a low risk of hypoglycemia in insulin-naive patients with type 2 diabetes: a 26-week, randomized, controlled, multinational, treat-to-target trial: The BEGIN LOW VOLUME trial. Diabetes Care. 2013;36:2536-2542.

30. Bode BW, Chaykin LB, Sussman AM, et al. Efficacy and safety of insulin degludec $200 \mathrm{U} / \mathrm{mL}$ and insulin degludec $100 \mathrm{U} / \mathrm{mL}$ in patients with type 2 diabetes (Begin: Compare). Endocr Pract. 2014;20:785-791.

31. Evans M, Khunti K, Mamdani M, et al. Health-related quality of life associated with daytime and nocturnal hypoglycaemic events: a time trade-off survey in five countries. Health Qual Life Outcomes. 2013;11:90

32. Freemantle N, Evans M, Christensen T, Wolden ML, Bjorner JB. A comparison of health-related quality of life (health utility) between insulin degludec and insulin glargine: a meta-analysis of phase 3 trials. Diabetes Obes Metab. 2013;15:564-571.

33. Hemkens LG, Grouven U, Bender R, et al. Risk of malignancies in patients with diabetes treated with human insulin or insulin analogues: a cohort study. Diabetologia. 2009;52:1732-1744.

34. Colhoun HM; SDRN Epidemiology Group. Use of insulin glargine and cancer incidence in Scotland: a study from the Scottish Diabetes Research Network Epidemiology Group. Diabetologia. 2009;52: 1755-1765.

35. Fagot J-P, Blotiere P-O, Ricordeau P, Weill A, Alla F, Allemand H. Does insulin glargine increase the risk of cancer compared with other basal insulins? A French nationwide cohort study based on national administrative databases. Diabetes Care. 2013;36:294-301.

36. Kurtzhals P, Schäffer L, Sørensen A, et al. Correlations of receptor binding and metabolic and mitogenic potencies of insulin analogs designed for clinical use. Diabetes. 2000;49:999-1005

37. Agin A, Jeandidier N, Gasser F, Grucker D, Sapin R. Glargine blood biotransformation: in vitro appraisal with human insulin immunoassay. Diabetes Metab. 2007;33:205-212.

38. Nishimura E, Sorensen AR, Hansen BF, et al. Insulin degludec: a new ultra-long, basal insulin designed to maintain full metabolic effect while minimizing mitogenic potential. Diabetologia, 2010;53 Suppl 1:S388 (Abstr 974) 
Diabetes, Metabolic Syndrome and Obesity: Targets and Therapy

\section{Publish your work in this journal}

Diabetes, Metabolic Syndrome and Obesity: Targets and Therapy is an international, peer-reviewed open-access journal committed to the rapid publication of the latest laboratory and clinical findings in the fields of diabetes, metabolic syndrome and obesity research Original research, review, case reports, hypothesis formation, expert

opinion and commentaries are all considered for publication. The manuscript management system is completely online and includes a very quick and fair peer-review system, which is all easy to use. Visit $\mathrm{http}: / / \mathrm{www}$.dovepress.com/testimonials.php to read real quotes from published authors.

Submit your manuscript here: http://www.dovepress.com/diabetes-metabolic-syndrome-and-obesity-targets-and-therapy-journal 